\title{
Evaluation's identity: Who are we, why are we here, and what does our future look like?
}

\author{
Katrina L. Bledsoe
}

\section{Background and introductions}

What now seems like a lifetime ago, I had the distinct honour of being asked to be a keynote speaker at the Aotearoa New Zealand Evaluation Association, better known as ANZEA. When I was first asked, I was elated — and stunned. I wondered what could I say that would be inspirational and hadn't already been said before? My New Zealand colleagues were already actively engaged in conducting culturally responsive evaluation, equitable evaluation, transformative evaluation, and culturally responsive indigenous evaluation with a focus on sovereignty and social justice, long before this talk. Greater voices in the field of evaluation than mine (e.g., Hall, 2018; Hood et al., 2015; House, 2017) had already spoken. Additionally, my perspective is decidedly North American, and US-based at that. But, we always need reminders to continue to be the people we say we are, to continue to champion causes of humanity, equity, human rights, and social justice.

What made the invitation easier to accept was the theme of the conference in 2018: Evaluation for Change, Change for Evaluation. 
I am always seeking personal transformation and change: the bad habits that keep me from being the best person I can be, the habits and circumstances that sometime hamper innovation. I thought the title of my address was fitting since I am a social psychologist first and foremost, and to me, identity and understanding of the self are a key component to one's ability to contribute in a meaningful way to a civil society and to true salvation of the self. But what happens when we lose focus and do not understand our identity?

I often see transformation and the response to this question on a larger organisational, systemic level. And now, at the time of this writing while residing in the United States, a raging pandemic is sickening and killing our citizens; there are continued threats to our democracy, the very fabric of the country; and there is continued civil unrest with racial and cultural injustice. Economic despair rages; environmental neglect and abuse continue; and the disconnect between people, and our souls grows. Our general way of life has stopped working for us, although we long to return to it. It should not be surprising that I find that transformation is needed more than ever.

I find that the field-and by extension the practice-of evaluation is the same. We have struggled with an identity crisis since the time evaluation deemed itself a field that scholars recognise (e.g., Scriven, 1991). Although we have cobbled together a story and background, our understanding of what identity is and what it looks like is limited. Who are we? Why are we here? What do evaluators do? What should we be doing? How are we connected to the world, systems, and one another? And, after figuring all that out, what does our field and practice look like in the future? But before tackling these big questions, a little about me ...

I was born and raised Catholic in Riverside, California in the United States, a sleepy and conservative desert suburb of Los Angeles, 
post-civil rights movement. It is the land of the Cahuilla, Gabrielino, Serrano, Luise'o, Chemehuevi, and Mojave tribes. My family is a product of many racial backgrounds, including African, Asian, Native American, and Northern European, although, like most people, I am unsure of the details. I am the first born on my mother's side of the family not to have picked cotton for employment. Two of my great grandmothers were born into slavery. And I grew up in a household that prized and prioritised community service and choosing professions that put the value of others at the forefront.

I went to college with the desire to be a clinical psychologist because I was moved by the human spirit. But when I engaged in coursework, I quickly became disillusioned by the reality that psychology was considered the "study of human behaviour" and that anything beyond that was tacitly, derogatorily referred to as, "the helping profession". I realise now how limited those definitions were, in my own world and in the field of psychology. Like most students trying to find an identity, I became enamoured with other disciplines. I was enthralled with economics, particularly macroeconomics, because it had a broad view of why and how the markets and our economic system worked. Including how people worked within a system, and what affected a market, making it rise and fall (ultimately, people in their angst and joy). Alas, it again was about the human spirit, so I resumed my pursuit of psychology, but instead, social psychology, because life is a combination of our dynamic characteristics, the contexts in which we live, and the dynamic cultures to which we are aligned. Although I loved (and still love) some of the theories that were representative of that interplay, something was missing.

When I entered my doctoral programme in applied social psychology, I stumbled upon evaluation. Evaluation made sense in being able to make use of academic knowledge for social change, and in a best-case scenario, social justice and transformation. My particular 
focus on social change was not especially welcomed because social justice, culture, and context were seen as a threat to the world ordermuch like it is now.

My training was primarily in theory-driven evaluation, which seemed appropriate since I saw value in those social psychological theories, especially those that were focused on intergroup relations, prejudice, stereotyping, influence, and attitude change. When I left graduate school for the East Coast, my focus became increasingly on culture, cultural responsiveness, and context in evaluation settings. I moved on from college teaching in a small township 5 minutes away from Trenton, New Jersey to the more expansive community settings of the Washington D.C. Metropolitan area.

Almost 20 years after graduating from the doctoral programme, my career has become focused on social change, equity and racial equity, and social justice in the field of evaluation, and being able to use evaluation to create change and transformation in organisations and people. I regularly receive calls from organisations that profess a need to be equitable, to be culturally responsive. They all call with a need to change and/or transform, however sincere-or insincerethat declaration may be. Many of my evaluation colleagues find themselves in similar situations. This is often beyond the scope of what the field has traditionally addressed, but evaluators are finding that the role has expanded beyond the technical. For example, I only spend about a third of my time conducting activities that evaluators are primarily trained to do (e.g., methods, statistics, data collection, and analysis). The rest is spent trying to understand communities, understand the context and the political landscape, figuring out how systems work, and helping organisations make sense of their own identities, and transformation.

As I continue to mature, both personally and professionally, I find that I am always looking forward to what I will have accomplished 
in life to further humanity, that make us accepting of a civil and loving society. My daily questions are less about the technical issues and more about, "Does this show love? Care? Grace?" I believe that, increasingly, practitioners of evaluation will wonder the same. Indeed, this wonderment has already begun within the American Evaluation Association: the 2020 Annual Conference focused on how evaluators shine their light, and the plenaries focused on love, and how evaluation might help engender it. But to move forward, often one must take stock of the past. The ANZEA conference theme, although in 2018, was forward-thinking then and now is even more so. The focus of my thoughts in this article then, is on the field and practice's identity, its history, and what I believe we should look forward to being and doing in the future.

I propose that change for evaluation is primarily about embracing our humanity, vulnerability, and our ability and courage to love, show care, and grace, even at the risk of one's livelihood or life. I also propose that the change in how we view and think about evaluation must begin with thinking of evaluation as a service to our fellow human beings. Evaluation cannot call itself innovative, service-oriented, or evolutionary without transformational change in the way that we do our work, consideration of our future history, and most importantly, our identity.

\section{How did we get here? One evaluator's perspective on the history of the field}

As I mentioned earlier in this article, understanding the history and context of the field and practice of evaluation, overlaid with a, "Why is it like that?" analysis, are key characteristics of my personality. It's in my nature to analyse the history I was taught about the field, and how its current state of being, however unstable at this moment, is perceived. My understanding of evaluation theory was ultimately 
shaped by the original evaluation theory tree (Christie \& Alkin, forthcoming). The roots of that tree were grounded in social-science theory, and in particular, US-framed social-science theory. The tree, as originally conceived (it has been updated with a social justice branch by Christie and Alkin (forthcoming), Mertens and Wilson (2019), and, more recently, Thomas and Campbell (2020)), focused on the branches of evaluation use, evaluation methods, and values. The trunk was comprised of those who were considered the forefathers of the field.

I was also taught that the field, and in particular the practice of evaluation, really solidified when US Federal agencies such as the Department of Education began asking for "objective" social-science research to provide data and recommendations to social problems being addressed by government-funded education programmes (Shaddish et al., 1991). But even that timing is up for debate. Gargani (2011) noted that it was Ralph Tyler in the late 1800s who first focused on educational assessment. Earlier still, Scriven (1991) had suggested that the field had auspicious beginnings with the early Greek philosophers and has been around for perhaps thousands of years. But there is one overarching connection between all of the "beginnings": they were all White men who claimed that the field started with them, and, with a specific set of social-science methods, defined by the aforementioned group. With that theoretical grounding and background, my colleagues and I were trained that there was a hierarchy of how we did evaluation, the methods we would use to conduct it, and what would be considered valid and credible evidence.

We, of course, want to acknowledge the arguments by those who might want to extol how far we've come as a field by noting that evaluation mostly has disavowed the randomised control trial as the only design to provide valid and credible evidence. Certainly, conversations in both scholarly and informal spaces, and statements 
put out by evaluation associations around the world, have acknowledged as such within the last several years (e.g., American Evaluation Association [AEA], 2011; Canadian Evaluation Society [CES], 2015). But more than once we evaluators continue to compare methods and outcomes to this standard. And too often we have undertaken our evaluations using the same methodological procedures that have been sanctioned as good or at least usable science. Yet, we know that what is considered a valid method can be exclusionary of other communities, particularly those that have been historically marginalised. Our prioritisation of some methods over others has created a "zero sum" all-or-nothing perspective: if you don't use these methods then any information you might generate outside of these doesn't really count. The researcher is to conduct an objective study with people labelled as the subjects. In this case, the researcher/evaluator has become judge and jury in determining how data will be analysed, what information people will be privy to, who will be represented, and what evidence will be considered credible and usable by those who are considered to be in power. It is a powerful historical narrative and one that serves as the foundation of our current existence as a discipline.

Given our history, it is necessary to explore the role evaluators have played, and what we have been asked to do. Evaluators are often asked to provide credible and valid data that can be used for what is considered rational and logical decision making. We're brought in as the so-called objective word and vision to often partisan programmes and initiatives (e.g., House, 2017).

Evaluation's reputation and history has been based upon the assumption of rationality and pragmatism. But whose rationality and pragmatism? We know that evaluators have striven to remain above the so-called fray; we've generally shied away from advocacy and complexity in our work, although this perspective has recently been up for debate (e.g., EVALTALK, 2019). Yet in trying to abstain from 
complexity, feelings, the unknown, and what is considered "irrational" thinking, we have subtly become complicit in the ills we say we're providing rational information and data to solve: violations of human rights, racism, sexism, anti-immigration, etc.

How has a field that has often declared its dedication to standing up for righteousness by being objective, become subjective and complicit? House (2017) noted that evaluation in its current state could be co-opted for injustice, particularly if the programmes and initiatives that were developed were unjust and unfair from the start. Evaluation is often a reflection of the programmes and initiatives that are developed so it makes sense that it, too, would engage in suppressive behaviour (e.g., Caldwell \& Bledsoe, 2019; House, 2017). Even within its own walls, evaluation has struggled to be inclusive. Hall (2018) and others (e.g., Hood, 2004; Thomas \& Campbell, 2020) have noted that, until recently, the voices of evaluators of colour and women who were intimately involved in the founding of the field were not recognised as part of the theoretical tree: neither were their contributions.

Historically, there are those who will argue that we are closer to technicians, the hands of funders' and organisational clients' ideas and that we serve to help those constituents (e.g., Shaddish et al., 1991). Still others will say that the role has expanded into providing technical assistance to those who need evaluation support; coaching to those seeking to understand how best to use evaluation; and planning for organisations' future programmatic developments (e.g., Shaddish et al., 1991). By our historical account these latter aspects are not necessarily considered evaluation. But I contend that our current identity and history is limited and limiting for evaluators. We do infinitely more than we have identified, and these practices must be considered evaluation. To truly change, transform, and grow, evaluation and evaluators must look to what it/they will be doing-if they 
haven't done so already_and how that new identity and role will serve social justice and the pursuit of a civil society.

\section{What is evaluation moving towards?}

So, if we have been limiting our view of our identity and our role, what should evaluators be looking towards? How should we be thinking about evaluation? If we're not the court jester (e.g., Patton, 2008), or judge and jury (e.g., Scriven, 1991), or serving at the pleasure of the funder (e.g., Shaddish et al., 1991), what should we be doing? What is evaluation moving towards and how will it transform? Let's talk about what we are moving towards in the 21st century.

Jara Dean-Coffey's (2017) pioneering work in the Equitable Evaluation Initiative (EEI) speaks to the larger issue at hand about love, service, and grace towards one another: that evaluation must be in service of equity within a civil society. We cannot be afraid to speak on behalf of equity. Although her work has primarily been focused within the philanthropic sector, Dean-Coffey encourages funders, organisations, evaluators, and communities to undertake evaluation work to answer critical questions about systems, populations, and contexts and how issues of inequity influence the functioning of these. Finally, she calls for evaluative work to be multiculturally valid and focused on participant ownership and leadership. This is markedly different from our beginnings, although this would fit within the vision of that giant of methods, Donald Campbell (Shaddish et al., 1991): that is, the vision of the evaluator in service of society, rather than as an all-powerful determinant of society and its outcomes. To that end, I believe the following must be part of the move towards social justice and social change.

Giving back to and investing in communities and establishing relationships and advocacy. Evaluators should be expected to be engaged in long-term — rather than time-limited-partnerships with 
communities, where we are as invested in the development of communities' wellbeing as they are. The expectation from communities is that we will make a long-term commitment, give back, and redress any breaches of the relationship and social contract (Kirkhart, 2013; McGoff, 2011). A second consideration should be that evaluators can no longer stand on the sidelines. We must step into the advocacy space. While this seems to be the antithesis to what we say we do, we are increasingly asked to advocate on behalf of the communities with whom we work, and their values. Many of these values focus on social justice issues such as human rights, anti-racism, pro-immigration, and civil rights. We are asked to forsake the sidelines to become a key player stating one's unsaid values and beliefs. In short, evaluators are increasingly being asked to use evaluation to address inequity rather than tacitly contribute to it (e.g., Patton, 2019).

Encouraging open access of evaluation to communities. The field is becoming less elitist. There is a demand from communities to know more about evaluation, to work with evaluators who are culturally and contextually aware, and to have self-determination and control over their own destinies (e.g., Waapalaneexkweew, 2018). With evaluation becoming more "open access", communities can have control over how it is used, rather than having funders make those decisions. I believe such a shift in ownership increases the credibility of evaluation, enhancing its influence and perhaps its utility. Yet we must always be aware of the known and unknown danger of evaluation being co-opted for unproductive and discriminatory acts against humanity under the guise of community. We have seen this before; for example, the curious case of Henrietta Lax (Skloot, 2010); indigenous nations being brutally killed and sidelined (e.g., Waapalaneexkweew, 2018), and the imprisonment of Latinx children in holding pens at the US border taken from their families, perhaps never to be reunited (e.g., Rampell, 2020), among other unjust acts. 
Serving as agents for social change and addressing inequity. Evaluation has generally shied away from identifying itself as a tool for social change. Again, this goes back to the idea that we need to remain objective, something evaluators continue to struggle with because we equate and conflate the idea of objectivity with rationality. Serving as an advocate or an agent for change is in direct conflict with this perspective. Currently within the American Evaluation Association (and I suspect other associations) this argument existstaking a side is often thought to indicate irrationality (lack of objectivity), while remaining above the fray, having the so-called ability to see all sides and be swayed by none is still considered by many to be pure, uncontaminated, and above reproach (e.g., Reiss \& Sprenger, 2020). This is a very secular perspective and leads to lack of compassion and empathy, for both require feelings, subjectivity, and connections to people on an emotional level.

Certainly, there are plenty of participatory and collaborative approaches such as culturally responsive evaluation, equity-focused evaluation, indigenous, and transformative evaluation (Mertens, 2008; Waapalaneexkweew, 2018) that are grounded in the belief that it is evaluation's duty to ensure social justice not only in evaluation, but in civil society in general. These approaches are helpful in holding us accountable and vigilant to possible atrocities. Yet, I've heard many evaluators try very hard to make the distinction that evaluators do not create social change: they instead support those who create social change and address inequity. But I believe that those colleagues who make that claim are sorely misguided. I would argue that evaluation's very purpose is about trying to address issues of inequity by its illumination of facilitators and barriers to equity and, subsequently, equality. That is certainly the expectation of those who commission evaluations that champion equity, but even more importantly, those collaborators, partners, and communities with whom we work. 


\section{So then, what should be evaluation's new focus?}

As I mentioned earlier, my perspective on evaluation has changed. For me, it is now less about the technicality of the work or the methods or even the data: it is much more about service to and love for one another, how we show one another kindness and respect. Focusing on love and service changes the evaluator's role from judge and jury to member of communities, organisations, societies, and families. It means that the heart of the evaluator grounds the work.

Evaluation can arguably be described as being predicated upon social-science principles that are focused on interventions and those interventions' effect upon certain populations. While people are the recipients of said interventions, the goal and focus is to discern the effectiveness of the intervention, programme, or strategy either to scale up or serve as a model to service a specific population of people (e.g, Lipsey, 1989). We're more concerned about efficaciousness or efficiency of the programme in alleviating some kind of malady, or perhaps concerned about something that could possibly be used for good (e.g., Lipsey, 1989). While there is interest in how participants will react and if they demonstrate change, it is really about the validity, reliability, and credibility of the intervention and its ability to address issues that concern the masses.

In conducting people-centred evaluations, the focus is on the community and people in the evaluative context. Rather than singularly focusing on one's reactions, a people-centred evaluation starts with a recognition of communities within contexts, their experiences with power and privilege, their ecosystem, their historical backgrounds, lived experiences, and their assets (e.g., Bledsoe, 2018; Dart $\&$ Barry, 2006). In this type of evaluation, it is less about the evaluand and more about how people will thrive as a result of it, and their participation in the evaluative process. To that point, people-centred 
evaluations have a different perspective. It means that evaluations are designed to recognise participants' full humanity imbued with culture, background, and context, and treat it with respect and honour. And it means partnership with communities, and being led by communities. The focus is on using evaluation as a tool for change, for making people's lives better, serving and loving them, and not for the agendas of funders, and certainly not for the sake of a so-called intervention.

But to be people-centred in our work, we must do work on ourselves. We must connect with our full humanity. We cannot empathise or sympathise with people unless we understand our own perspectives and ourselves in general (e.g., Symonette, 2015). Evaluators often believe that if they truly connect with communities in an authentic_-indeed, loving — way this will somehow taint the data, make it invalid. However, I contend that an inability to connect with people actually invalidates the data and its credibility. Instead of connecting and understanding the context, society, and issues that comprise a programme, strategy, and the like, we end up relying on our own privileged and often disconnected perspective. We must understand that we cannot take our traditional perspectives about evaluation and shoehorn them into people-centred approaches; instead, there must be a full transformation of the field, theorists, and practitioners in which culture, issues of equity, and human rights are the foundation of the evaluation and evaluation purpose. We cannot address social justice or racial equity if we do not place that as a stance in our work. The American Evaluation Association's long-standing Public Statement on Cultural Competence (2011) states that cultural competence, and by extension responsiveness, respect, humility and so forth, is a stance not a destination. A stance requires constant self-reflection and monitoring of character and core values. Stances require us to address our long-standing implicit—and explicit—biases. They 
require us to admit and face the historical backgrounds, contexts, and systems that shape us including those that both facilitate-and hinder-our best selves.

To this end, my colleague and friend Thomas Archibald and his colleagues (Vo \& Archibald, 2018) have discussed evaluative thinking extensively. When engaging in evaluative thinking, the evaluator must be thoughtful and self-reflective in the work they do. This includes thinking strategically about the evaluation and evaluative process and what factors influence and affect both. I particularly like Karen Kirkhart's (2013) work as a strategy to engage in evaluative thinking. Her focus on culture and validity helps the evaluator better understand the context and what it means to conduct evaluation in communities and our responsibility to those communities. Equally, Hazel Symonette's (2015) integral evaluator model reminds the evaluator that evaluation isn't for evaluation sake, but that it is also about the evolvement of the evaluator and evaluation transformation. Specifically, she notes that the evaluative self must be considered in three strategies: (1) calibrating the self within the context that includes understanding people, voices, and perspectives; (2) knowing the self within the context by understanding that our core character and values matter to both ourselves and to others; and (3) activating the self in context which is the integration of the former two in being able to glean insights, note assumptions, and so forth. In Symonette's model, the evaluator is constantly engaging in self-reflection and constantly monitoring how one enters settings and communities, and how an evaluator's presence will inevitably influence the context and the evaluation.

\section{What are some concrete considerations to think about in the field's new world?}

Evaluators must consider and embrace new strategies to conduct their 
practice in a manner that is knowledgeable about and respectful of an inconsistent and changing world, else "evidence" that is provided is suspect. During this time of upheaval, evaluation is at a crossroads. Although traditional methods and tools continue to dominate how evaluators think and do their work and how funders and requestors ask for that work, I believe we can think innovatively, and reprioritise evaluation's values of what it does and why it does it. A move towards people-centred versus evaluand-centred evaluation demonstrates a need to use methods and perspectives that are representative of communities. More importantly, this transformed perspective would require us to put equity at the forefront, by prioritising the humanity of communities who have been historically marginalised, enslaved, or have been the focus of genocide and/or eugenics (e.g., Herrnstein \& Murray, 1994; Skloot, 2010). Although this is a much larger conversation, I'd like to discuss four aspects that I think must be considered: community engagement; getting to root cause; design thinking and innovation; and data visualisation and presentation.

Community engagement. Evaluators have made significant progress in reaching out to communities and trying to provide feedback to and solicit input from communities. We now call them collaborators and sometimes partners. Indeed, many colleagues know that I have been talking about the National Institutes of Health's (NIH's) adapted model of community engagement for some time (NIH, 2011) which includes outreach to communities, consultation about the process, involvement in the process, collaboration as two invested groups, and partnership with communities. That being said, although many of us have talked about stakeholder and community engagement on a regular basis, when we are challenged to assess how much engagement there is or the quality of that engagement, we find that we have not gotten beyond the consult stage. In reality, evaluators still struggle to have meaningful engagement with communities and 
often come with a social science research-focused mentality which prioritises the needs of the research and the researcher.

But what does it look like when it works well? My New Zealand Indigenous colleagues (e.g., Cram, 2009; Wehipeihana \& McKegg, 2018) have often talked about authentic community engagement that starts with self-determination, sovereignty, and leadership in the evaluative process. As an example, my colleagues and I at Education Development Center have developed a partner-focused relationship with the Coalition of Schools Educating Boys of Color (COSEBOC) and we have worked closely as a partner on several projects focused on racial equity in education. We have worked as a blended team and with COSEBOC as the lead we have been able to forge authentic community partnerships throughout New England by: (a) having COSEBOC lead the work; (b) ingratiating and working closely with COSEBOC and their community partners; and (c) working to understand what evaluative practices are best suited for the communities we're working with. This isn't always easy-our team is diverse in terms of experiences, and in what we view as "good" science. But looking to the community for leadership (as opposed to seeing them as people we occasionally interact with) has: (1) ingratiated us to the community; (2) led to valid and credible evidence that the community believes and claims; and (3) led to a long-lasting and trusting relationship. But to move to such a relationship, evaluators must redefine their role and what they perceive as their power which is often masked as their expertise (COSEBOC, 2021).

Getting to root cause. Increasingly, we are hearing conversations that address issues of root cause, rather than symptomology. When we talk about root cause, we're referring to the origins of the problem - what started it, the history of it, and the antecedents and foundations. We're not talking about root cause in the abstract, we're talking about what is actionable; how the injustice and breach of 
trust will be alleviated. This requires a level of honesty that sometimes leads to unpleasant issues. Thus, the role of evaluation and the role of evaluators are not objective or comfortable. I have had success in working with funders and communities about using the "Five Whys" strategy often used in business organisations in trying to get down to root cause. The strategy is simple: to drill down to root cause, you ask why a problem occurs five times. In work with a local philanthropic organisation focused on the material and child health of African American women, we were able to ask a series of "why" questions that helped to uncover the continued hurt owing to racist policies, and the distrust that the community harboured not only about the local healthcare providers, but with the county and state health departments as well.

Design thinking and innovation. When Design Thinking (Kelly \& Kelly, 2013) became trans-disciplinary/trans-sector I realised that business and business development had figured out a way to open access to social-science theory and methods in a way that was people-centred rather than intervention- or research-centred. Design thinking, which was originally rooted in the planning and designing of products, is a strategy that allows for product developers to be free to think broadly and uninhibited beyond traditional spaces to arrive at contextually and culturally specific solutions. It focuses not on what's wrong but what is the asset that can be raised to create a product that is most connected with people and their respective lives (Kelly \& Kelly, 2013). There isn't one strategy but many, and one should expect many answers from the strategies used. I know many of our colleagues have used design thinking techniques to collaborate, partner, and connect with communities. For instance, journey mapping is a way to gain an understanding of the historical milestones — and resonating emotions_- and can provide a grounding for understanding the assumptions, landscape, and key tipping points 
that underlie goals and impacts that are most important to communities. Journey mapping allows organisations to look historically at where they have come from and where they might go. It helps to pinpoint where the issues of change might be the most conducive or painful to press upon. We have found this technique helpful in uncovering the past and continued impact of institutional and systemic racism. Design thinking techniques can allow us to address head-on issues that stem from inequity, trauma, and hurt, and allow us to seek to transform them.

Data visualisation and presentation. One of the concerns that I hear from communities is that the data gathered and discussed isn't presented in a way that is representative of the context, culture, community, and system. Partners have often voiced concern that they are forced to present their work using a deficit model which focuses on how much more improved they are from bad and/or pathologised. Instead, they want to illustrate and present from an asset-based model with challenges versus a deficit model that shows improvement from one's inevitable circumstances (e.g., Bledsoe, 2014).

Stephanie Evergreen (2013) and Ann Emery (2021) have challenged evaluators to think through how the presentation and visualisation of data is not only a way to engage communities but also a way to rethink how stories are told and from what perspective. The use of pictorials and rethinking how graphs are presented can influence what issues become elevated. For instance, logic models and theories of change are ubiquitous and are the first visuals used to represent issues, programmes, and initiatives and how they work and how they influence. The use of traditional logic models often does not consider the issues of the context and culture, or issues of history, political framing, and systems. To that end, Shai Fuxman and his colleagues at Education Development Center (Fuxman, cited in Bledsoe, 2014) developed separate visual logic models that addressed 
the unique and contextual issues of four specific ethnic communities (African American, Latino, LGBTQI2A, Indigenous) for a youth-led and focused health programme. Each of these models represents the communities in which the youth populations reside.

\section{Concluding remarks}

Arguably, the COVID-19 pandemic has gripped and paralysed the world. It has exposed the issues that continue to plague us as a global society: inhumanity, inequity, our avoidance of social justice, and overt denigration of human rights and the environment. This is especially true of the United States, one of the richest nations, which has led the way in the world sickness and death and the inequity that has perpetuated both (e.g., World O Meters, 2021). Although many of us long to go back to past lives lived, I see this as an opportunity-a calling if you will — to transform the way we conduct our lives, who we choose to centre in those lives, how we conduct our relationships, and how we treat the environment in which we all live.

As mentioned earlier, evaluators struggle with their place in doing that work. Instead, we say that we are not engaged in the social change of the world, mainly because our definition is limited of who is doing it and what's considered a meaningful change. Sociology posits that "social change is the alteration of mechanisms within the social structure characterised by changes in cultural symbols, rules of behavior, social organisations, or value systems" (e.g., Dunfey, 2019). If social change is the alteration of social structures, then I would encourage us to think about our current role in upholding an inequitable and unequal structure by the information that we provide to inform policies and programmes, how we engage with funders and communities, and how the information is used (Caldwell \& Bledsoe, 2019; House, 2017). If we consider our role in that structure, would it not seem plausible that evaluators and evaluation can be engaged in 
social change by challenging, for instance, what is considered credible evidence? Championing how information can be used? Standing with and supporting marginalised voices and pursuing authentic partnerships? Broadening participation in a field that many have deemed closed and for experts? Using data to expose and challenge policies that are inhumane, inequitable, and racist? Maybe the social change role of the evaluator is not so much about how we function on the ground, but in how we stand up for the work that we do, the communities with whom we partner and are in relationship with, and the structures and systems our work influences.

My hope for the field includes making peace with our internal struggle of what is considered good evaluation and how it's done, taking the time to self-reflect what the purpose is, what our role should be, and how we will train and support the evaluative community as it goes about its work. In short, I hope our conversations and plans will help prepare us to better love and serve one another in this life.

\section{References}

American Evaluation Association. (2011). American Evaluation Association public statement on cultural competence in evaluation. Author. https://www. eval.org/ccstatement

Bledsoe, K. L. (2014). Truth, beauty, and justice: Conceptualizing House's framework for evaluation in community-based settings. New Directions in Evaluation, 71-82. https://doi.org/10.1002/ev.20086

Bledsoe, K. L. (July, 2018). Evaluation's identity: Who are we, why are we here, and what does our future look like. Aotearoa New Zealand Evaluation Association.

Caldwell, L. D., \& Bledsoe, K. L. (2019). Can social justice live in a house of structural racism? A question for the field of evaluation. American Journal of Evaluation, 40, 6-18. https://doi.org/10.1177/1098214018815772

Canadian Evaluation Society. (2015). Honouring the truth: Reconciling for 
the future: Summary of the final report of the Honouring Truth Commission. Author.

Christie, C., \& Alkin, M. (2013). An evaluation theory tree. In C. Christie \& M. Alkin (Eds.), Evaluation roots: A wider perspective of theorists' views and influences (pp. 11-58). Sage.

Coalition of Schools Educating Boys of Color. (2021). Student centered learning. Funded by the Nellie Mae Education Fund.

Cram, F. (2009). Maintaining indigenous voices. In D. M. Mertens \& P. I. Ginsberg (Eds.), Handbook of social research ethics (pp. 308-322). Sage. https://doi.org/10.4135/9781483348971.n20

Dart, J., \& Barry, P. (2006). People-centered evaluation. Australasian Evaluation Society Conference, Darwin, Australia.

Dean-Coffey, J. (2017). Equitable evaluation framework: Framing paper. Equitable Evaluation Initiative. https://rive.google.com/file/d/1sXIGQW 6SUIwc04XLfjeiMaIP4C99lnHt/view.

Dunfey, T. S. (19 May 2019). What is social change and why should we care? https://www.snhu.edu/about-us/newsroom/2017/11/what-is-socialchange\#:-:text=Sociologists $\% 20$ define $\% 20$ social $\% 20$ change $\% 20$ as,long $\% 2$ Dterm $\% 20$ consequences $\% 20$ for $\% 20$ society

Emery, A. (2021). Depict data studio. https://depictdatastudio.com/

EVALTALK. (2019). Evaluation is not a tool for social change. American Evaluation Association.

Evergreen, S. (2013). Presenting data effectively: Communicating your findings for maximum impact. Sage.

Gargani, J. (2011). More than 25 years of the American Journal of Evaluation: The recollections of past editors in their own words. American Journal of Evaluation, 32, 428-447. https://doi. org/10.1177/1098214011412175

Hall, M. (2018). Evaluation's race problem in the U.S.: A call to action for the profession and the American journal evaluation. American Journal of Evaluation, 39, 569-583. https://doi.org/10.1177/1098214018792624 
Herrnstein, C., \& Murray, R. (1994). The bell curve: Intelligence and class structure in American life. Free Press.

Hopson, R. K. (2003). Overview of multicultural and culturally competent program evaluation issues, challenges and opportunities. Social Policy Research Associates.

House, E. (2017). Evaluation and the framing of race. American Journal of Evaluation, 38, 167-189. https://doi.org/10.1177/1098214017694963

Hood, S. (2004). A journey to understand the role of culture in evaluation: Snapshots and personal reflections of one African American evaluator. New Directions for Evaluation, 102, 21-37. https://doi.org/10.1002/ev.113

Hood, S., Hopson, R., \& Frierson, H. (2015). Continuing the journey to reposition culture context in evaluation theory and practice. Information Age.

Hood, S., Hopson, R., \& Kirkhart, K. (2015). Culturally responsive evaluation. In K. Newcomer, H. Hatry, J. Wholey (Eds), Handbook of practical program evaluation (4th Ed., pp. 281-317). Jossey-Bass

Kelly, D., \& Kelly, T. (2013). Creative confidence: Unleashing the creative potential within us all. Crown Publishers.

Kirkhart, K. (2013). Advancing considerations of culture and validity: Honoring the key evaluation checklist. In S. I. Donaldson (Ed.), The future of evaluation in society: A tribute to Michael Scriven (pp. 129-160). Information Age.

Lipsey, M. (1989). Design sensitivity: Statistical power for experimental research. Sage.

McGoff, C. (2011). The primes: How any group can solve any problems. Victory Publishers.

Mertens, D. M. (2008). Transformative research and evaluation. Guilford Press.

Mertens, D. M., \& Wilson, A. T. (2019). Program evaluation theory and practice second edition: A comprehensive guide. Guilford Press. 
National Institutes of Health. (2011, June). Principles of community engagement (2nd ed.). NIH Publication No. 11-7782.

Patton, M. Q. (2008). Utilization-focused evaluation. Sage.

Patton, M. Q. (2019). Blue marble evaluation: Premises and principles. Sage.

Rampell, C. (23 November 2020). Families like this one were torn apart at the

border. The U.S. still hasn't made things right. Washington Post.

Scriven, M. (1991). Evaluation thesaurus. Sage.

Shaddish, W. R., Cook, T. D., \& Leviton, L. C. (1991). Foundations of evaluation: Theories of practice. Sage.

Skloot, R. (2010). The immortal life of Henrietta Lacks. Crown Publishers.

Reiss, J., \& Sprenger, J. (2020). Scientific objectivity. Stanford Encyclopedia of Philosophy. https://plato.stanford.edu/entries/scientificobjectivity/\#:-:text=Scientific\%20objectivity\%20is\%20a\%20 property,name $\% 20 \mathrm{a} \% 20$ few $\% 20$ relevant $\% 20$ factors.

Symonette, H. (2015). Culturally responsive evaluation as a resource for helpful-help. In S. Hood, R. Hopson, \& H. Frierson (Eds.), Continuing the journey to reposition culture context in evaluation theory and practice (pp. 109-130). Information Age.

Thomas, V., \& Campbell, P. (2020). Evaluation in today's world: Respecting diversity, improving quality and promoting usability. Sage.

Vo, A., \& Archibald, T. (2018). New directions for evaluative thinking. New Directions for Evauation, 158, 139-147. https://doi.org/10.1002/ev.20317

Waapalaneexkweew (Nicole R. Bowman-Farrell, Mohican/Lunaape). (2018). Looking backward but moving forward: Honoring the sacred and asserting the sovereign in Indigenous evaluation. American Journal of Evaluation, 39, 543-568. https://doi.org/10.1177/1098214018790412

Wehipeihana, N., \& McKegg, K. (2018). Values and culture in evaluative thinking: Insights from Aotearoa New Zealand. New Directions in Evaluation, 158, 93-107. https://doi.org/10.1002/ev.20320 
World O Meter. (2021). United States coronavirus cases. https://www. worldometers.info/coronavirus/country/us/

\section{The author}

Katrina L. Bledsoe, Education Development Center/Katrina Bledsoe

Consulting/Strategic Learning Partners for Innovation

Email: katrina.bledsoe@gmail.com 